\title{
Der Verkäuferregress im deutsch-französischen Rechtsvergleich
}

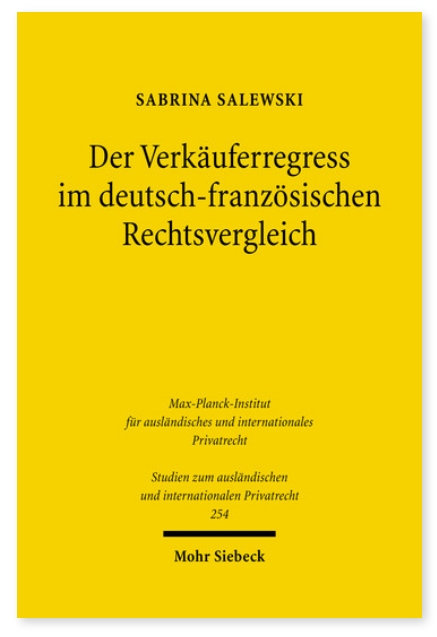

2011. XXIV, 348 Seiten. StudIPR 254

ISBN 978-3-16-151439-5

DOI 10.1628/978-3-16-151439-5

eBook PDF 79,00€

ISBN 978-3-16-150727-4

fadengeheftete Broschur 79,00€
Art. 4 der RL 1999/44/EG (Verbrauchsgüterkaufrichtlinie) verpflichtet die Mitgliedstaaten der EU u.a. zur Einführung einer Regelung zum Letztverkäuferregress. Während Deutschland sich bei der Umsetzung für einen Regress entlang der Lieferkette entschieden und die Rückgriffsmöglichkeiten des jeweiligen Verkäufers gegenüber seinem direkten Lieferanten vereinfacht hat, verweist der französische Gesetzgeber lediglich auf die principes du Code civil. Vor dem Hintergrund der immer wieder diskutierten Frage, ob die französische action directe als Vorbild für einen Direktanspruch des Letztverkäufers oder sogar des Verbrauchers gegen den Hersteller in Betracht kommt, untersucht Sabrina Salewski die Darstellung dieser »Prinzipien«, nämlich die allgemeinen Gewährleistungsvorschriften, die action directe sowie die action récursoire. Anschließend analysiert sie prozessuale Besonderheiten in Frankreich auf ihren Vorbildcharakter hin.

Sabrina Salewski Geboren 1982; Studium der Rechtswissenschaft in Trier und Indianapolis; 2010 Promotion in Trier und Paris; Rechtsanwältin (Associate) im Bereich Banking und Banking Litigation in Frankfurt/Main.
Jetzt bestellen:

https://mohrsiebeck.com/buch/der-verkaeuferregress-im-deutsch-franzoesischen-rechtsvergleich-9783161514395?

no_cache=1

order@mohrsiebeck.com

Telefon: $+49(0) 7071-923-17$

Telefax: +49 (0)7071-51104 